\title{
Ecological Regulation of Black Leaf Streak Disease Driven by Plant Richness in Banana Agroecosystems
}

\author{
Charlotte Poeydebat, ${ }^{\dagger}$ Dominique Carval, Philippe Tixier, Marie-Odette Daribo, and Luc De Lapeyre De Bellaire
}

First, second, and fourth authors: CIRAD, UPR GECO, F-97285 Le Lamentin, Martinique, France; first, second, third, and fifth authors: CIRAD, UPR GECO, F-34398 Montpellier, France; first, second, third, and fifth authors: GECO, University of Montpellier, CIRAD, Montpellier, France; and third author: Departamento de Agricultura y Agroforesteria, CATIE, Turrialba, Cartago, Costa Rica. Accepted for publication 30 April 2018.

\begin{abstract}
Black leaf streak disease (BLSD), caused by the fungus Mycosphaerella fijiensis, is an important threat to banana production. Although its control relies on costly and unsustainable use of fungicides, ecological regulation of BLSD linked to field-scale plant diversity has received little attention. We monitored banana phytometers in plots in banana-based fields where no fungicides were applied. Within each plot, we measured plant richness in three strata, canopy openness, necrotic leaf removal, Musa abundance and richness. We quantified ecological regulation of five BLSD parameters (inoculum sources, spore abundance, lesion density, incubation time, and the area under the disease progression curve) and identified, using structural

equation modeling, the characteristics of the plant community and the mechanisms likely responsible for the regulation. Regulation occurred, but most effectively before lesion formation, and was mainly related to plant richness between 1.5 and $5 \mathrm{~m}$ high. A barrier effect, rather than a dilution effect, more likely limited spore abundance. Our results support the hypothesis that the potential effects of plant richness on leaf-scale microclimate variability and on the diversity of epiphyllic microorganisms are involved in the regulation of incubation time and lesion density. Field-scale management of plant diversity may be a promising lever to foster ecological regulation of BLSD.
\end{abstract}

Bananas are widely grown in the tropical rain-fed regions of Africa, Asia, and Latin America, and their cultivation involves two main types of cropping systems: (i) the cultivation of a single cultivar of dessert banana for exportation (Musa acuminata, AAA, Cavendish subgroup) and (ii) the cultivation of a broader range of dessert or cooking cultivars for local use (Stover and Simmonds 1987). Bananas in both types of cropping systems are subject to black leaf streak disease (BLSD), which is one of the most important threats to banana and plantain crops and therefore to worldwide food security (Jones 2000; Pennisi 2010). This foliar disease, which is caused by an ascomycete, Mycosphaerella fijiensis, reduces plant photosynthetic capacity and crop yield (Mobambo et al. 1993) and also reduces fruit quality by causing premature ripening, which is a major constraint for crops grown for export (de Lapeyre de Bellaire et al. 2010). In export banana cropping systems, this quality reduction can result in complete crop loss and is mainly prevented by the repeated and costly use of fungicides (Churchill 2011; Marin et al. 2003). The application of fungicides for BLSD control in intensive cropping systems has created many economic and environmental problems (de Lapeyre de Bellaire et al. 2010; Risède et al. 2010). In addition, chemical control is unsustainable in the many countries where fungicide-resistant populations of M. fijiensis have been detected (de Lapeyre de Bellaire et al. 2009). Another limitation for control of BLSD with fungicides concerns smallholder farmers, who mostly grow bananas for local markets; such growers generally cannot afford fungicides and often experience BLSD-caused crop losses ranging from 20 to $50 \%$

${ }^{\dagger}$ Corresponding author: C. Poeydebat; E-mail: charlotte.poeydebat@inra.fr

Funding: This work was supported by CIRAD and was funded by the Project "Use of the biodiversity of Martinique to improve the functioning of agro-ecosystems" from E.U. FEDER (grant PRESAGE number 33157).

*The $\boldsymbol{e}$-Xtra logo stands for "electronic extra" and indicates that three supplementary figures and three supplementary tables are published online.

(c) 2018 The American Phytopathological Society
(Mobambo et al. 1993; Stover 1983). It follows that alternative methods of BLSD control are needed for bananas grown for both export and local consumption.

Mycosphaerella fijiensis forms two types of propagules: conidia through asexual reproduction and ascospores through sexual reproduction (Meredith and Lawrence 1969). The BLSD cycle begins when ascospores or conidia settle on the leaf surface. After a short period of epiphyllic growth ( 2 to 3 days), germ tubes penetrate the leaf stomata (Fouré and Moreau 1992) (Fig. 1). Under optimal environmental conditions, the first symptoms appear on susceptible cultivars after 10 to 14 days (Marin et al. 2003). The symptoms then gradually evolve from small brown streaks (stage 1) to necrotic spots (stage 6). Conidia are produced on young streaks and are water or wind-dispersed over very short distances (Rieux et al. 2014). The time between the infection and the beginning of the production of conidia is termed the conidial latency and in the case of M. fijiensis it corresponds to the incubation period. Ascospores are produced at later stages (necrotic stages) and are wind-dispersed after perithecia burst following rainfall events (Gauhl 1994). Ascospores are dispersed farther than conidia (Rieux et al. 2014) very likely because the former (i) are projected in the air during the perithecia burst, (ii) have a more aerodynamic shape, and (iii) are smaller. The following processes in BLSD development are greatly influenced by temperature, humidity, and leaf wetness: germination and mycelial growth (Jacome et al. 1991); incubation period and symptom development (Fouré and Moreau 1992; Jacome and Schuh 1992); and sporulation (Fouré 1982; Gauhl 1994; Jacome and Schuh 1993). Both the production of ascospores and conidia are consequently affected.

Studies have suggested that fungal diseases in general could be regulated through (i) structural characteristics of the plant community (such as canopy structure) and (ii) compositional characteristics, particularly the composition of the plant community in terms of hosts, nonhosts, and the variable susceptibility among hosts (Boudreau 2013; Newton et al. 2009; Tivoli et al. 2013). Canopy structure might affect environmental conditions on leaves and thereby affect spore germination, infection, and the incubation 
period (Sahile et al. 2008). The phyllosphere microbial community could also be influenced by canopy structure and community composition (Newton et al. 2009) and could reduce the epiphyllic growth of the pathogen and therefore reduce infection (Ceballos et al. 2012). Canopy structure might also influence inoculum interception by leaves (Schoeny et al. 2008) and physical properties favoring spore dispersal such as wind turbulence and the kinetic energy of raindrops (Boudreau 2013; Boudrot et al. 2016; Tivoli et al. 2013). The introduction of nonhost plants directly affects disease epidemics by limiting inoculum sources and spore propagation via host dilution and barrier effects (Mundt 2002; Ratnadass et al. 2012). Ultimately, the diversification of the plant community in a field may affect resource availability or soil properties, which could subsequently modify crop nutrition and stresses and the physiological resistance of the crop to the disease (Haggar et al. 2011; Mobambo et al. 1994; Ratnadass et al. 2012; Schroth et al. 2000).

Although banana fields cultivated by smallholders for local markets often contain plants other than banana, little attention has been paid to how the richness of the plant community at the fieldscale contributes to the ecological regulation of BLSD. By ecological regulation, we mean the limitation in disease resulting from ecological processes arising from plant community characteristics or management (excluding the application of fungicides). A previous study reported that intercropping with cassava did not substantially affect BLSD incidence and severity (Emebiri and Obiefuna 1992), while other studies showed that shading provided by overstory trees could reduce disease severity perhaps partly because of a lack of dew (Calpouzos 1955; Norgrove and Hauser 2013).
However, the relationships between plant richness and BLSD development parameters have not been studied.

In this study, we monitored banana phytometers in field plots distributed along a gradient of plant richness. Our first objective was to assess field-scale ecological regulation of different stages in the BLSD cycle. Our second objective was to identify the characteristics of the composition or the management of the plant community underlying the ecological regulation. Finally, we discuss the underlying ecological mechanisms as well as practical implications for plant community management to optimize BLSD control.

\section{MATERIALS AND METHODS}

Study region and agroecosystem characterization. We conducted a field study in the Talamanca Reserve $\left(9^{\circ} 00^{\prime}-9^{\circ} 50^{\prime} \mathrm{N}\right.$, $\left.82^{\circ} 35^{\prime}-83^{\circ} 05^{\prime} \mathrm{W}\right)$, Costa Rica, between July 2014 and January 2016. The mean annual temperature and air relative humidity measured between August 2014 and July 2015 at several points within our sampling zone were $24.9 \pm 1.2^{\circ} \mathrm{C}$ and $91.2 \pm 6.1 \%$, respectively. The mean annual rainfall in the Talamanca Reserve is about $3500 \mathrm{~mm}$ (Deheuvels et al. 2012). The tropical humid conditions of this area are conducive to BLSD (Gauhl 1994; Jacome and Schuh 1992). The area has alluvial soils or Ferrisols that are derived from volcanic materials (Winowiecki 2008). In the Talamanca Reserve, plantains and bananas are grown in long-cycle shifting cultivation systems under remnant forest trees and without the use of agrochemicals. These agroforestry fields are generally longestablished and contain several Musa genotypes. Plant diversity in

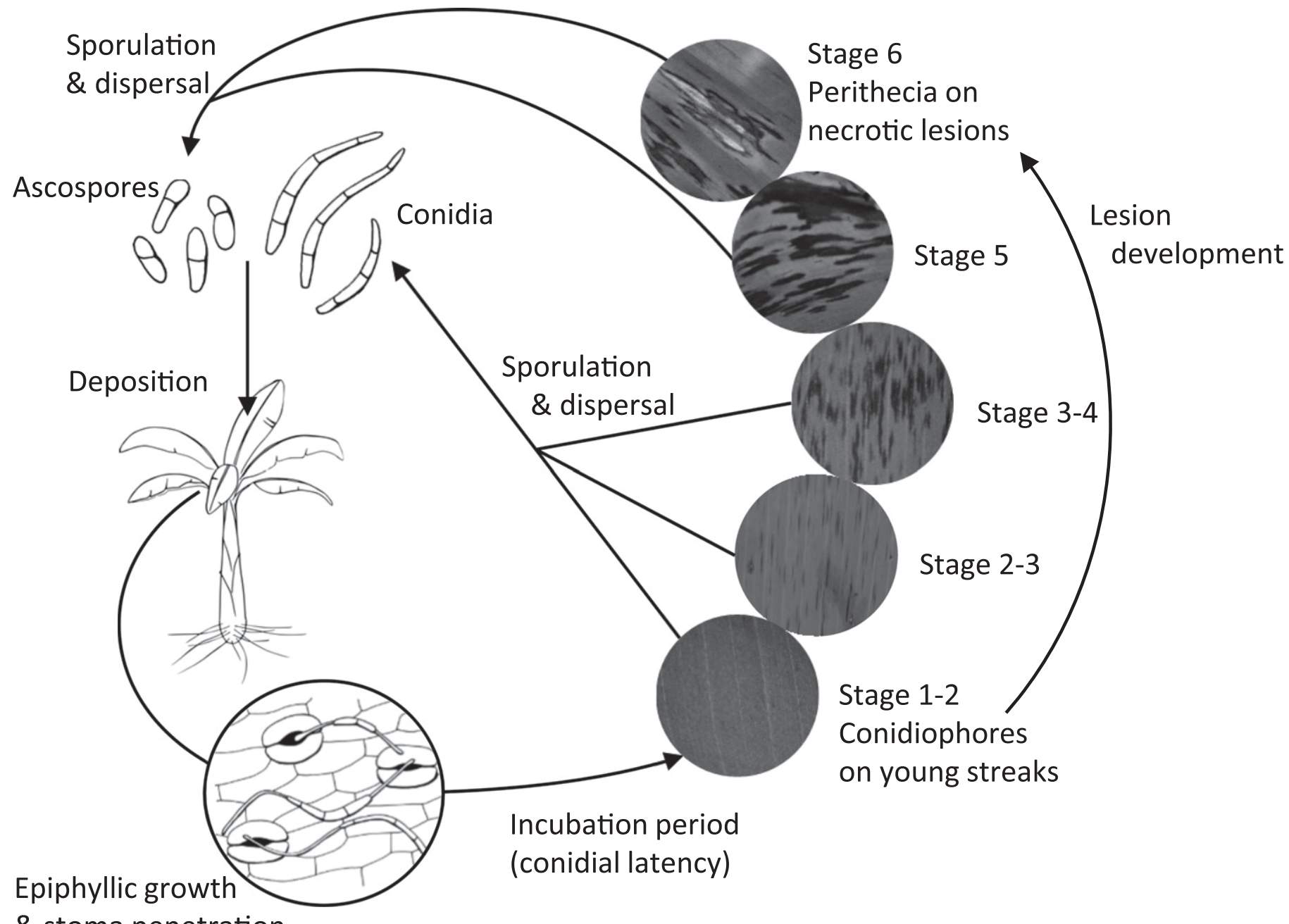

\& stoma penetration

Fig. 1. Epidemic cycle of the black leaf streak disease (BLSD) caused by the airborne ascomycetous fungus Mycosphaerella fijiensis. 
these fields is variable (Somarriba and Harvey 2003), and non-Musa plants can include forest trees, cultivated trees (e.g., cocoa and citrus trees), medicinal plants, weeds, and ground crops (e.g., cassava and taro). We selected eight plant-diversified, bananabased fields in which farmers never applied fungicides for BLSD control. The only control method used by certain farmers was the prophylactic removal of necrotic leaves. To account for the effect of this practice on the disease, we expressed the annual frequency of necrotic leaf removal in terms of a leaf removal index. All eight fields were located within a $5-\mathrm{km}$ radius and were therefore exposed to very similar regional and landscape conditions.

We used BLSD-susceptible banana plants (Musa acuminata triploid AAA, Cavendish subgroup, Grande Naine cultivar) (Fouré et al. 1990) as phytometers (provided by AgriBio, Costa Rica); these were obtained by in vitro propagation, which limited the genetic variation among plants. A total of 68 phytometers were distributed in the eight farmer fields. Minimum and maximum numbers of phytometers per field were, respectively, 5 and 14. Each phytometer was located in the center of a 10-m-radius circular plot that was considered the sampling unit. Plot locations were chosen (i) to make the best use of within-field heterogeneity to cover a wide gradient of plant community complexity, and (ii) far enough inside the fields to avoid edge effect (more than $10 \mathrm{~m}$ away from the edge, most often inside wide fields). Each phytometer was placed $1.5 \mathrm{~m}$ distant from an existing banana plant which was either a Cavendish cultivar Grande Naine, a Cavendish cultivar Gros Michel or a Plantain, according to most abundant cultivar in the plot. Within one field, adjacent phytometers were at least $20 \mathrm{~m}$ apart so that two plots never overlapped.

Canopy openness above the phytometer was assessed in each plot as the percentage of open sky seen from beneath the canopy. To this end, we photographed a $180^{\circ}$-hemispherical area of the canopy above the phytometer using a camera with a fisheye lens (Nikon NC-E8 Fish-Eye Converter). The camera was oriented skyward and was maintained horizontally just above the phytometer foliage. The hemispherical photographs were analyzed using the Gap Light Analyzer (GLA Version 2.0) image processing software (Frazer et al. 1999).

In each plot, we identified the genotype of each banana plant and measured its distance to the phytometer. We calculated Musa abundance and richness. In addition, each non-Musa plant rooted within the plot was assessed for height and was identified based on recent literature (Gargiullo et al. 2008) and local knowledge. When a species could not be identified, it was designated as a morphospecies according to its morphology; this enabled the calculation of richness. The plant community was subdivided into three height strata: (i) a low stratum, ranging from 1.5 to $5 \mathrm{~m}$ high, (ii) an intermediate stratum, ranging from 5 to $10 \mathrm{~m}$ high, and (iii) a high stratum, above $10 \mathrm{~m}$ high (Fig. 2). We did not consider plants below $1.5 \mathrm{~m}$ high in this study. Non-Musa plants between 1.5 and $5 \mathrm{~m}$ high were assumed to directly interact with the leaves of banana plants (which develop in this height range) and modify microclimate, wind turbulence, microbial community, and lateral transport of inoculum within the banana foliage zone. Plants in the upper strata may affect banana plants on a larger scale than plants in the low-stratum because of their larger size and because they may have architectural traits that affect vertical spore transportation, rainfall interception, shading, and wind turbulence at the plot scale. A plant was considered to belong to a given stratum when the center of its crown was located between the lower and upper height limit of the stratum. In each stratum, non-Musa plant richness was calculated as the total number of species.

Disease cycle monitoring. As described in the following sections, we determined the level of local inoculum sources, the number of spores reaching the phytometer foliage, the duration of the incubation period, and the density of lesions on a phytometer leaf. We also determined the necrotic leaf area on each phytometer at several times during the experiment to obtain a disease progression curve for each phytometer. The timing of experimental operations is summarized in Figure 3.

Level of local inoculum sources (IS). The ascospore is the most important type of spore for M. fijiensis dispersal (Rieux et al. 2014). Because $M$. fijiensis ascospores are produced on necrotic leaves (Burt et al. 1999), the number of necrotic leaves on a banana plant was used to indicate its importance as a source of ascospores. Susceptibility to BLSD was expected to vary among Musa genotypes (Fouré et al. 1990; Meredith and Lawrence 1970). In each plot, we determined the number of necrotic leaves of each Musa genotype present by sampling one to three specimens of each genotype (according to the abundance in the plot), and averaging values when more than one specimen was sampled. We assumed that plants from a given Musa genotype in a given plot had the same number of necrotic leaves. We also assumed that the infectious potential of a given banana plant depended on its distance to the phytometer because the probability that a spore settles on a target host decreases with distance (Rieux et al. 2014). Therefore, we calculated the level of local IS as the sum of the ratios between the number of necrotic leaves and the distance (d) to the phytometer of all the banana plants in the plot.

Spore abundance (SA). To assess the abundance of spores that could reach the phytometer foliage (compared with the level of local inoculum sources), we used a trap plant (a young banana plant obtained from in vitro micropropagation and of the same genotype as the phytometer) from which we had removed all leaves except the youngest one (to eliminate the possibility of self-inoculation). We placed this trap plant on top of a 2-m-high stake directly above the phytometer on the day the leaf began to unfurl (i.e., stage B) (Brun 1963). After 7 days in the plot, the trap plants were removed from the field and were placed under $70 \%$ artificial shading in individual, transparent polyethylene plastic bags that enabled gas exchange. This eliminated the possibility of new infections and provided conditions (high humidity and leaf wetness) that were conducive for conidia and ascospores to infect and produce lesions. We monitored the trap plants daily to detect lesion apparition and assess incubation period. After twice the duration of the incubation period minus 2 days (Rieux et al. 2014), we counted the number of stage 1 or 2 lesions (Fouré 1985) on the trap plant leaf. We divided this number of lesions by the leaf area and the number of days the leaf was exposed to spores in the field (which was always 7 days) to determine the number of lesions per leaf area unit per exposure day. This provided an estimate of the density of lesions that should be observed on the phytometer leaves in the absence of factors that limit the disease in the field. We refer to this variable as SA.

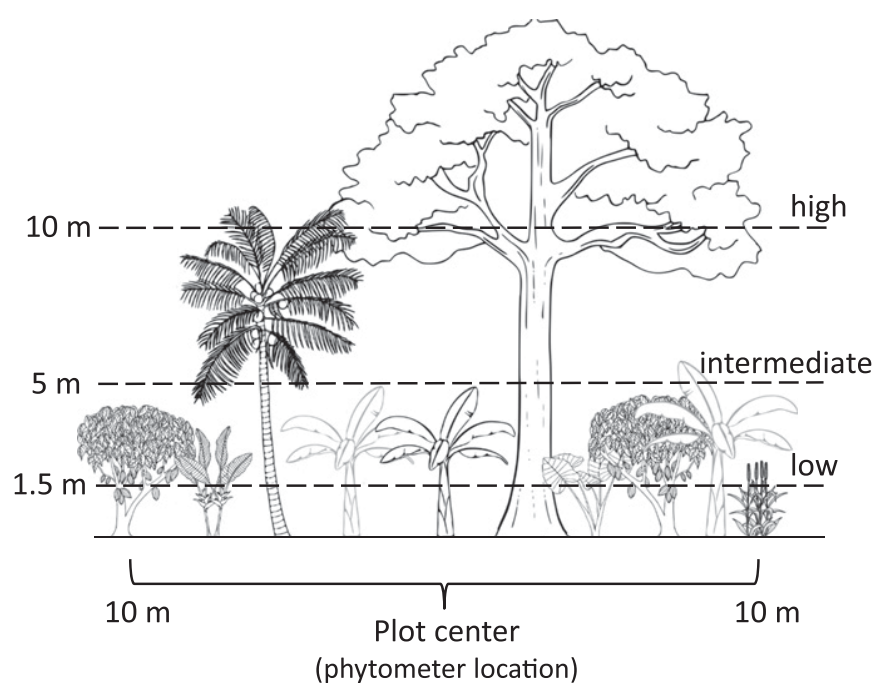

Fig. 2. Representation of the three height strata in which plant richness was separately assessed within a plot. The darker banana plant represents the phytometer located in the center of the 10-m-radius circular plot. 
Unexposed young plants were directly placed in the postexposition conditions (under shading in plastic bags) and monitored to control for absence of new infections after removal from the plot.

Incubation period (IP) on phytometers. In August 2015, we began monitoring the youngest leaf of each phytometer at stage B (Brun 1963) to assess the duration of the incubation period and the number of spores developing into lesions under field conditions. The duration of the incubation period was assessed as the number of days between the first day the monitored leaf was exposed to spore deposition (i.e., stage B) (Brun 1963) and the day that the first stage 1 lesions (Fouré 1985) appeared (Fouré 1982).

Lesion density $(L D)$ on phytometers. At a time corresponding to twice the duration of the incubation period minus 2 days (Rieux et al. 2014), we counted the number of lesions on the phytometer's monitored leaf. At this time, spores of the first generation present on the leaf were assumed to have germinated while spores of later generations were assumed not to have formed new lesions. We divided the number of lesions by the leaf area to obtain the density of lesions on each phytometer. We then divided the density of lesions by the duration of the incubation period to account for the relationship between time of exposure and number of deposited spores. Therefore, the density of lesions was expressed as the number of lesions per unit leaf area per exposure day.

Disease severity. The necrotic leaf area (NLA) of each phytometer was assessed at several times (from two to six times according to the duration of the monitoring period of the phytometer) during the study as the total area of leaves $\left(\mathrm{cm}^{2}\right)$ covered with necrosis. We calculated the cumulated NLA over time from the beginning to the end of the phytometer monitoring period, and characterized the disease progress curve, i.e., the curve of NLA cumulated over time. We calculated the area under the disease progression curve (AUDPC), expressed as square centimeters per day, as a measure of disease severity (Donzelli and Churchill 2007). Thirteen phytometers died before the end of the study because of harsh conditions (especially in terms of light competition) and therefore had different monitoring period lengths. For comparison purposes, we calculated the standardized AUDPC by dividing the AUDPC by the number of days of the monitoring period. We refer to this variable as $\mathrm{AUDPC}_{\mathrm{t}}$ or disease severity and it was expressed as square centimeters of necrotic leaf.

Assessment of BLSD regulation. We quantified the regulation of BLSD in terms of four parameters. First, we assessed

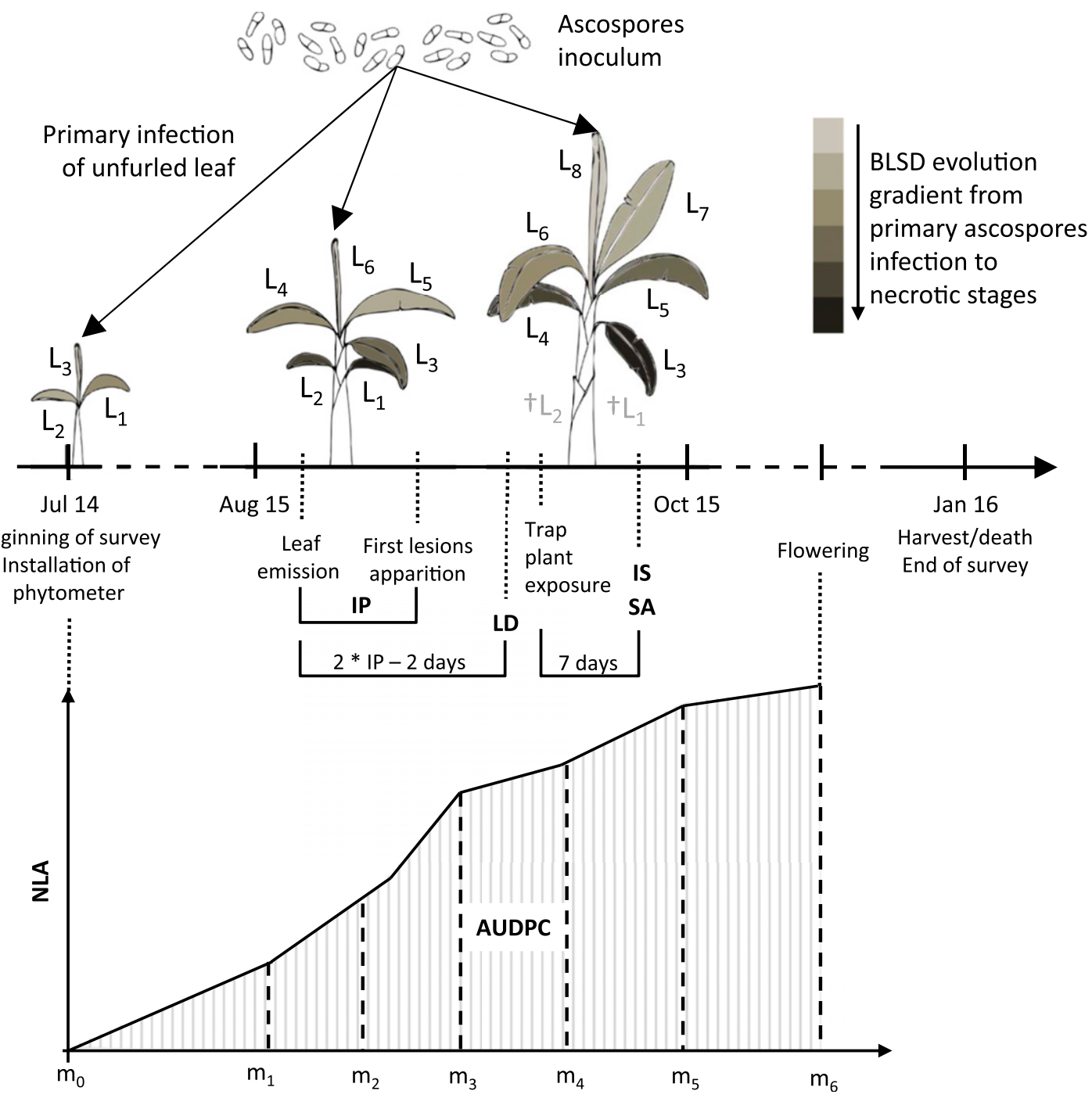

Fig. 3. Chronology of disease parameters' assessment in relation with the phenology of the phytometer. Each new leaf of the phytometer was primarily infected by a new cohort of Mycosphaerella fijiensis ascospores at the time of its emission (unfurled leaf). The evolution of the cohort of ascospores after primary infection was correlated with the age of the leaf. The grayscale indicates the stages of evolution of the disease (including the primary infection and the five stages of the disease). Inoculum sources (IS), spore abundance (SA), lesion density (LD), and incubation period (IP) were assessed once for each phytometer during the survey, between August and October 2015. The necrotic leaf area $\left(\mathrm{NLA}, \mathrm{cm}^{2}\right)$, used to calculate the area under the disease progression curve (AUDPC), was assessed several times during the survey between July 2014 and flowering (or the end of the survey if the phytometer did not flower). The sizes of time intervals in the figure are not necessarily proportional and representative of actual time intervals. The numbers of the leaves are given as an example. L: leaf (the number corresponds to the leaf rank); m: measurement (the number corresponds to the repetition of the measure); $\uparrow$ : dead leaf. 
the regulation of spore abundance by comparing the SA to the level of IS. To do so, we fitted a $y=a x /(b+x)$ envelope-curve to the subsample of points "enveloping" the scatter plot of spore abundance versus level of inoculum sources. This subsample of points was obtained by selecting for each $x$ value the highest $y$ value, only if $y_{x}$ was superior to $y_{x-1}$. The envelop-curve represented the potential spore abundance that could be expected for each level of local inoculum sources according to our data. For each phytometer, the regulation of spore abundance was calculated as the difference between observed spore abundance and the potential spore abundance according to the envelop curve. Second, we assessed the regulation of infection efficiency as the difference between the LD on the phytometer and the SA, both expressed as the density of lesions per exposure day. Third, we assessed the regulation of incubation time as the difference between the duration of the incubation period observed on the trap plant under controlled, conducive conditions and the duration of the IP observed on the phytometer under plot conditions. Fourth, we assessed the regulation of disease severity by comparing the observed $\mathrm{AUDPC}_{\mathrm{t}}$ to the observed LD. Following the same procedure as above, we fitted an $y=a^{*} \log (b x)$ envelope-curve to the subsample of points "enveloping" the scatter plot of $\mathrm{AUDPC}_{t}$ versus LD. For each phytometer, the regulation of disease severity was assessed by calculating the difference between observed AUDPC $C_{t}$ and potential AUDPC $C_{t}$ expected according to the envelop-curve. For each BLSD parameter, we standardized the measures of regulation by dividing them by the maximal value and we averaged all the standardized measures to obtain a mean standardized regulation value.

Plant community characteristics related to BLSD regulation. We investigated the potential effects of (i) plant richness in different height strata, (ii) canopy openness, (iii) Musa richness, (iv) Musa abundance, and (v) necrotic leaf removal frequency on the BLSD parameters (IS, SA, IP, LD, and AUDPC $_{t}$ ) at the field scale. We built a structural equation model (SEM) composed of five linear mixed submodels describing the sequential relationships among the disease parameters as well as the potential effect of regulatory factors on these parameters based on hypothetical mechanisms (Table 1). For normally distributed data, we used the lme function (nlme R package) (Pinheiro et al. 2017). When response variables were nonnormally distributed and overdispersed, we used the glmmPQL function (MASS R package) (Venables and Ripley 2002) to fit a quasi-mixed model (Bolker et al. 2009). Although we emphasized local-scale processes, we accounted for field-scale determinism; for example, we accounted for field management history by introducing a field factor as a random intercept effect in all submodels, except for the duration of the incubation period. In the latter case, we hypothesized that microclimate and especially leaf wetness would affect the duration of the incubation period (Jacome and Schuh 1992). To test for the effect of such unmonitored microclimate conditions that were assumed to vary with phytometer location, we introduced

TABLE 1. List of submodels constituting the structural equation model (SEM) describing the relationships between black leaf streak disease (BLSD) parameters and the composition and the management of the plant community ${ }^{\mathrm{a}}$

\begin{tabular}{ll}
\hline SEM submodels & \\
\hline Response variable & \multicolumn{1}{c}{ Explanatory variables } \\
\hline IS & $\mathrm{MR}^{1}+\mathrm{MA}^{2}+\mathrm{NLR}^{3} \mathrm{CO}^{4,8}+\mathrm{LSR}^{5,6,7,8}+\mathrm{ISR}^{5,6,7,8}+\mathrm{HSR}^{5,6,7,8}$ \\
SA & $\mathrm{IS}^{9}+\mathrm{CO}^{4,10}+\mathrm{LSR}^{6}+\mathrm{ISR}^{6}+\mathrm{HSR}^{6}$ \\
IP & $\mathrm{SA}^{11}+\mathrm{CO}^{4,8}+\mathrm{LSR}^{5,8}+\mathrm{ISR}^{5,8}+\mathrm{HSR}^{5,8}$ \\
LD & $\mathrm{SA}^{12}+\mathrm{CO}^{4,8}+\mathrm{LSR}^{5,7,8}+\mathrm{ISR}^{5,7,8}+\mathrm{HSR}^{5,7,8}$ \\
AUDPC & $\mathrm{LD}^{11}+\mathrm{IP}^{13}+\mathrm{CO}^{4,8}+\mathrm{LSR}^{5,6,7,8}+\mathrm{ISR}^{5,6,7,8}+\mathrm{HSR}^{5,6,7,8}$ \\
\hline
\end{tabular}

SEM a priori hypotheses

Mechanisms

References

${ }^{1}$ Because sensitivity to BLSD differs among Musa genotypes, Musa richness will reflect the heterogeneity of the cultivar mix in terms of sensitivity and determine the level of inoculum sources in a plot.

${ }^{2}$ Musa abundance is associated with host dilution effects.

${ }^{3}$ Removing necrotic leaves responsible for spore production will limit the inoculum sources.

${ }^{4}$ Canopy openness can reduce BLSD severity by affecting microclimate and air and water dynamics.

5 Plant richness is associated with canopy structure heterogeneity and therefore can affect the microclimate at field and leaf scales.

6 Plant richness is associated with canopy structure heterogeneity and therefore can affect spore dispersal through spore interception and modification of within-canopy air currents.

${ }^{7}$ Plant richness is associated with the diversity of leaf substrates and subsequently the diversity of epiphyllic microorganisms that can have antagonistic interactions with $M$. fijiensis during its epiphyllic growth.

${ }^{8}$ Microclimate affects germination, mycelial growth, incubation time, and symptom development.

${ }^{9}$ Spore abundance is directly and positively related to the level of inoculum sources.

${ }^{10}$ Microclimate affects sporulation.

${ }^{11}$ Lesion development accelerates with the density of spores deposited on the leaf.

${ }^{12}$ Lesion density directly depends on the abundance of spores reaching the foliage.

13 Disease severity will be influenced by the duration of the infection period (i.e., necrotic formation is correlated to incubation period).

Fouré et al. 1990; Meredith and Lawrence 1970

Mundt 2002; Root 1973

Gauhl 1994; Marin et al. 2003

Calpouzos 1955; Mouen Bedimo et al. 2010; Norgrove and Hauser 2013; Mariño et al. 2016

Costes et al. 2013; Pincebourde and Woods 2012; Seidelmann et al. 2016

Boudreau 2013; Costes et al. 2013; Tivoli et al. 2013

Beveraggi 1992; Ceballos et al. 2012; Meredith 1970; Pincebourde and Woods 2012

Fouré and Moreau 1992; Jacome and Schuh 1992; Jacome et al. 1991

Burt et al. 1999; Gauhl 1994

Fouré 1982; Gauhl 1994; Jacome and Schuh 1993

Fouré and Moreau 1992; Fouré et al. 1984

Fouré and Moreau 1992

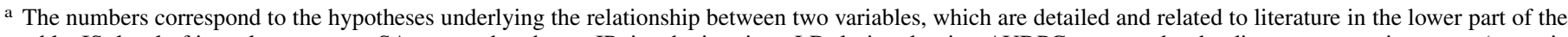

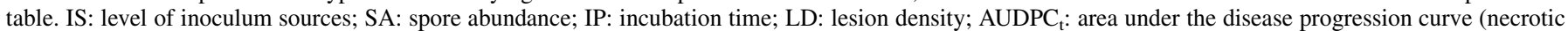
leaf area versus time) divided by the duration of the monitoring period; MR: Musa richness; MA: Musa abundance; NLR: necrotic leaf removal index; CO: canopy openness; LSR: low-stratum plant richness; ISR: intermediate-stratum plant richness; and HSR: high-stratum plant richness. 
the phytometer factor as a random intercept effect. Finally, we tested the validity of the overall structural model against our data.

Because the application of traditional SEM is restricted to normally distributed data, we used the generalized piecewise SEM approach (piecewiseSEM R package) (Lefcheck 2016), which includes a larger range of distributions (Shipley 2009). Goodnessof-fit of the overall model was evaluated using Shipley's test of direct separation (Shipley 2009). According to this method, the model is considered to be consistent with the data when no significant relationships among unconnected variables are omitted (Shipley 2000).

All statistical analyses were performed with R 3.2.3 (R Core Team 2014) and with an alpha level of 0.05 .

\section{RESULTS}

General description of the plant community in the plots. The names and abundances of the plant families and Musa genotypes in the three height strata of the plots are provided in Table 2. More details about the species in the plots are provided in Supplementary Table S1. The family Malvaceae, mainly represented by Theobroma cacao, was the most abundant plant group after Musa, especially in the low stratum. Total non-Musa plant richness varied from 0 to 16 species per plot and was on average $4.9 \pm 3.1$ species. Musa density ranged from 127 to 2548 plants per hectare and was negatively related to the abundance (linear regression $P$ value $=0.0082 ; R^{2}=0.09$ ) but not the richness (linear regression $P$ value $=0.89$ ) of plants from other taxa in the low stratum (Fig. 4). The richness and abundance of non-Musa plants in the low stratum were positively related (Poisson linear regression $P$ value $<0.001,37 \%$ of variance explained) (Fig. 5). As indicated by the numbers of necrotic leaves, the susceptibility to BLSD varied among Musa genotypes (Table 3).

Assessment of BLSD regulation. For a given level of IS, SA was always lower than the potential spore abundance expected from the envelope-curve (Fig. 6A). No lesions formed on the unexposed control plants, indicating that no new infections occurred after trap plants were removed from the plots. The LD observed on the phytometer was always lower than the SA (Fig. 6B). The incubation period assessed on the phytometers under plot conditions was generally longer than on trap plants under conducive conditions (Fig. 6C). For a given lesion density, the $\mathrm{AUDPC}_{\mathrm{t}}$ was generally lower than the potential AUDPC $_{t}$ expected from the envelope-curve (Fig. 6D). On average, spore abundance was reduced by $0.32 \pm 0.25$ spores per leaf $\mathrm{cm}^{2}$ per exposure day $\left(2.14 \pm 1.75\right.$ spores per leaf $\mathrm{cm}^{2}$ per week) as compared with the abundance of spores that was expected according to the envelope-curve. Infection efficiency was reduced by $0.44 \pm 0.29$ lesions per leaf $\mathrm{cm}^{2}$ per exposure day $(3.08 \pm$ 2.03 spores per leaf $\mathrm{cm}^{2}$ per week) compared with the abundance of spores deposited on the phytometer foliage. Incubation time was $7.14 \pm 5.10$ days longer on the phytometers under plot conditions than on trap plants under optimal conditions. Disease severity was reduced by $3.62 \pm 1.65 \mathrm{~m}^{2}$ of necrotic leaf area on average as compared with the expected disease severity based on lesion density. The mean standardized values of regulation were positive for all disease parameters (Fig. 7).

Plant community characteristics related to BLSD regulation. Our structural model fit the data well (Fischer's C statistic $=42.73$, $\chi^{2}$ test $P$ value $=0.145$ ), and 7 of the 28 tested relationships were significant (Fig. 8). All paths coefficients and $P$ values are presented in Supplementary Table S2. The level of IS was negatively related to the necrotic leaf removal index (standardized path coefficient $=$ $-1.53 \pm 0.20, P$ value $<0.001)$ and positively related to Musa abundance ( standardized path coefficient $=2.39 \pm 0.26, P$ value $<$ 0.001). Plant richness, Musa richness, and canopy openness were not significantly related to IS. SA was negatively related to the plant richness of the low stratum only (standardized path coefficient $=-1.36 \pm 0.58, P$ value $=0.022$ ) and positively related to IS (standardized path coefficient $=1.10 \pm 0.35, P$ value $=$ 0.003). The duration of the IP was positively related to low-stratum plant richness (standardized path coefficient $=0.55 \pm 0.21, P$ value $=$ 0.014 ) and negatively related to the density of lesions (standardized path coefficient $=-2.41 \pm 1.13, P$ value $=0.039$ ). The comparison of marginal (0.20) and conditional (0.90) R-squared values of the incubation time submodel showed that $70 \%$ of the variability in incubation time was explained by the phytometer random intercept effect. AUDPC $\mathrm{t}_{\mathrm{t}}$ was negatively related to the density of lesions ( standardized path coefficient $=-1.39 \pm 0.62, P$ value $=0.032$ ) . Otherwise, BLSD parameters were unrelated to each other. The variance of the field random effect was low in all submodels (Fig. 8). The variance and standard deviation of the phytometer random effect in the incubation time submodel were $22.14 \pm 4.71$.

\section{DISCUSSION}

Although ecological regulation of BLSD has been previously reported (Norgrove and Hauser 2013), the current study is the first to document field-scale ecological regulation of the following BLSD parameters: level of inoculum sources, spore abundance,

TABLE 2. Names and abundances of non-Musa plant families and of Musa genotypes in the experimental plots during the study ${ }^{\mathrm{a}}$

\begin{tabular}{|c|c|c|c|c|}
\hline \multirow[b]{2}{*}{ Stratum } & \multicolumn{2}{|c|}{ Non-Musa } & \multicolumn{2}{|l|}{ Musa } \\
\hline & Family & $\begin{array}{l}\text { Number } \\
\text { of plants }\end{array}$ & Genotype & $\begin{array}{l}\text { Number } \\
\text { of plants }\end{array}$ \\
\hline \multirow[t]{18}{*}{ Low } & Malvaceae & 542 & Gros Michel (AAA) & 1,095 \\
\hline & Poaceae & 65 & Plantain (AAB) & 619 \\
\hline & Arecaceae & 35 & Quadrado (ABB) & 197 \\
\hline & Myrtaceae & 32 & Lacatan (AAA) & 76 \\
\hline & Agavaceae & 32 & Primitivo (AA) & 39 \\
\hline & Fabaceae & 24 & $\begin{array}{l}\text { Chopo Colorado } \\
\text { (AAA) }\end{array}$ & 27 \\
\hline & Heliconiaceae & 22 & $\begin{array}{l}\text { Chopo Blanco } \\
\text { (AAA) }\end{array}$ & 19 \\
\hline & Urticaceae & 16 & Cavendish (AAA) & 19 \\
\hline & Rutaceae & 10 & Cocori & 12 \\
\hline & Euphorbiaceae & 9 & Balbisiana (BB) & 12 \\
\hline & Caricaceae & 6 & unidentified & 2 \\
\hline & Sapindaceae & 4 & & \\
\hline & Araceae & 4 & & \\
\hline & Boraginaceae & 2 & & \\
\hline & Lauraceae & 1 & & \\
\hline & Anacardiaceae & 1 & & \\
\hline & Unidentified & 83 & & \\
\hline & Total & 888 & Total & 2,117 \\
\hline \multirow[t]{11}{*}{ Intermediate } & Fabaceae & 15 & Gros Michel (AAA) & 43 \\
\hline & Malvaceae & 13 & Chopo Blanco (AAA) & 2 \\
\hline & Caricaceae & 8 & & \\
\hline & Boraginaceae & 8 & & \\
\hline & Anacardiaceae & 5 & & \\
\hline & Rutaceae & 4 & & \\
\hline & Cecropiaceae & 1 & & \\
\hline & Lauraceae & 1 & & \\
\hline & Meliaceae & 1 & & \\
\hline & Unidentified & 122 & & \\
\hline & Total & 178 & Total & 45 \\
\hline \multirow[t]{12}{*}{ High } & Boraginaceae & 61 & & \\
\hline & Fabaceae & 13 & & \\
\hline & Malvaceae & 9 & & \\
\hline & Anacardiaceae & 6 & & \\
\hline & Euphorbiaceae & 6 & & \\
\hline & Arecaceae & 4 & & \\
\hline & Cecropiaceae & 3 & & \\
\hline & Moraceae & 2 & & \\
\hline & Combretaceae & 1 & & \\
\hline & Lauraceae & 1 & & \\
\hline & Unidentified & 8 & & \\
\hline & Total & 114 & & \\
\hline
\end{tabular}

${ }^{\mathrm{a}}$ Abundances are totals for 68 plots in eight fields. 
incubation time, infection efficiency, and disease severity. Moreover, we identified the plant community characteristics associated with the regulation and quantified their effects on the parameters.

As expected, the level of inoculum sources reflected Musa abundance and the frequency of necrotic leaf removal. Our finding that necrotic leaf removal reduces inoculum is consistent with previous reports (Marin et al. 2003) and is reasonable because necrotic leaves can generate ascospores for up to 6 months (Gauhl 1994). If necrotic leaves are removed, we suspect that the contribution of host dilution (i.e., reduction of Musa abundance) to disease regulation would be substantially reduced. Although the susceptibility to BLSD varied among Musa genotypes, Musa richness did not determine the level of local inoculum sources. The most common Musa genotypes in our plots (Gros Michel and Plantain) are very susceptible to BLSD (Fouré et al. 1990; Meredith and Lawrence 1970) (Table 2 and 3), and other more resistant genotypes were perhaps too scarce in the plots to substantially affect the level of BLSD inoculum sources. Further investigations are required to determine the response of the disease to genotype mixing.

We found that the abundance of spores reaching the foliage of a phytometer was determined by the level of nearby (within $10 \mathrm{~m}$ ) inoculum sources. This was confirmed by comparing spore abundance measured on trap plants placed in field conditions before or after necrotic leaf removal in a subset of the plots (Supplementary Table S3). Moreover, on a commercial export banana farm where we conducted the same study, the application of fungicides drastically reduced the level of local inoculum sources (Supplementary Fig. S1). On this commercial farm, the abundance of spores reaching the trap plants (no fungicides were applied while the trap plants were in the plots) were also very low, suggesting that longdistance dispersal was not important. Together, those results show that local inoculum sources (sources of conidia and ascospores) may be more important than more distant inoculum sources in determining the abundance of spores reaching the foliage of a focal plant, which is contrary to the inferences of Burt et al. (1998). Our finding confirmed that it was relevant to search for factors regulating BLSD at a field scale.

Plant richness in the 1.5 to $5 \mathrm{~m}$ high stratum was negatively related to spore abundance. This suggests that plant richness within this height range supported local ecosystem processes that reduced the propagation of $M$. fijiensis spores. Plant-diversified ecosystems can reduce plant pathogen dispersal because of (i) increased distances between hosts and reduced connectivity between hosts' foliage, i.e., dilution effects (Mundt 2002; Root 1973); (ii) increased probability of spore interception, i.e., a barrier effect; and (iii)

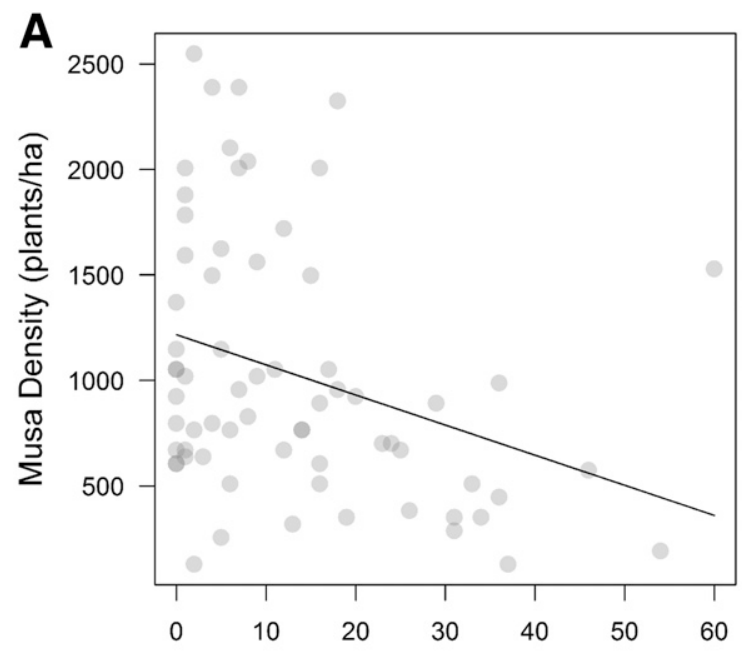

Low-stratum non-Musa plant abundance increased heterogeneity of the within-canopy wind patterns that affect airborne spore dispersal (Boudreau 2013; Costes et al. 2013; Tivoli et al. 2013). Although a dilution effect could have been associated with Musa abundance, our results showed that higher non-Musa plant richness was associated with a higher abundance of

TABLE 3. Numbers of black leaf streak disease necrotic leaves (NNL) on Musa genotypes $^{\mathrm{a}}$

\begin{tabular}{lc}
\hline Musa genotype & Number of necrotic leaves $($ mean \pm SD) \\
\hline Chopo Colorado (AAA) & $7.4 \pm 1.9$ \\
Gros Michel (AAA) & $6.9 \pm 3.6$ \\
Cavendish (AAA) & $6.1 \pm 3.0$ \\
Plantain (AAB) & $5.9 \pm 3.2$ \\
Lacatan (AAA) & $5.3 \pm 3.9$ \\
Cocori & $5.1 \pm 2.2$ \\
Chopo Blanco (AAA) & $4.4 \pm 2.9$ \\
Primitivo (AA) & $3.3 \pm 2.3$ \\
Quadrado (ABB) & $1.5 \pm 0.5$ \\
\hline
\end{tabular}

a Mean calculation accounts for the measures of NNL realized in all plots for a given genotype.

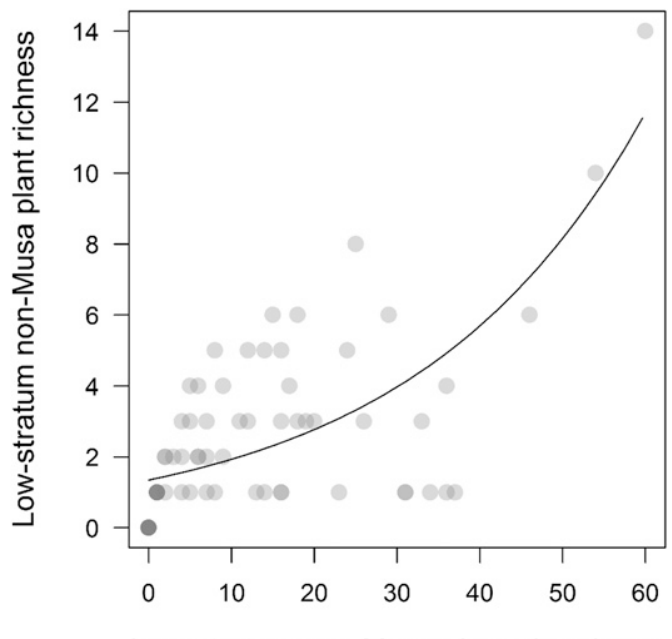

Low-stratum non-Musa plant abundance

Fig. 5. Relationship between low-stratum (1.5 to $5 \mathrm{~m}$ high) non-Musa plant richness and abundance. The line represents the Poisson linear regression; intercept estimate $=0.37(P$ value $=0.002)$; effect estimate $=0.12(P$ value $<0.001)$; null deviance $=145.5$; residual deviance $=91.3$; explained deviance $=54.2(37 \%)$.

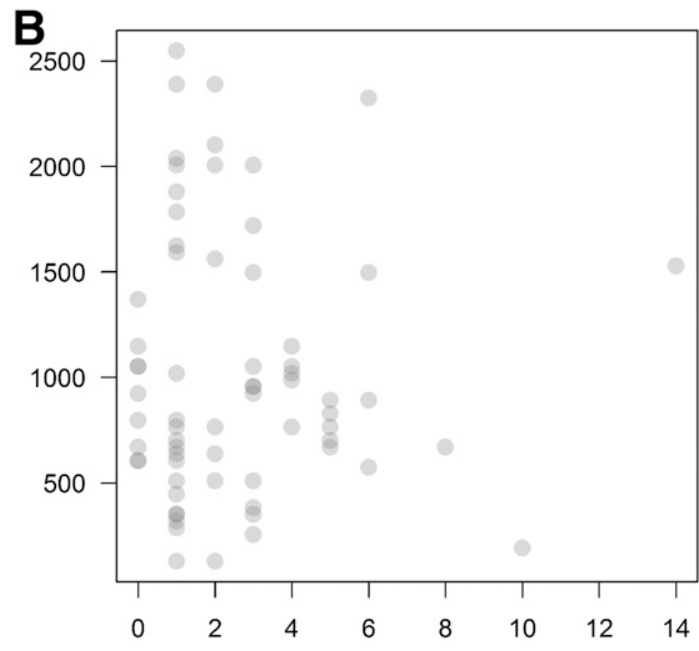

Low-stratum non-Musa plant richness

Fig. 4. Relationships between Musa density and A, low-stratum (1.5 to $5 \mathrm{~m}$ high) non-Musa plant abundance (linear regression $\mathrm{y}=-14.27 x+1216.81$; fixed effect $P$ value $\left.=0.0082 ; R^{2}=0.09\right)$ and $\mathbf{B}$, low-stratum non-Musa plant richness (nonsignificant linear regression; $P$ value $=0.89$ ). 
non-Musa plants but not necessarily with a lower abundance of Musa plants, suggesting that the regulation of BLSD spore abundance by plant richness was better explained by barrier or wind pattern effects than by a host dilution effect. Barrier effects or alteration of wind patterns in intercropping systems have previously been observed for the airborne fungus Alternaria solani, which causes tomato early blight (Gómez-Rodriguez et al. 2003). Disentangling barrier and wind-pattern effects is difficult in complex plant-diversified agroecosystems (Boudreau 2013). Lowstratum non-Musa plant richness was also associated with longer BLSD incubation periods. The richness of the plant community may result in a more heterogeneous canopy structure (more diverse forms of plants) and therefore may explain variations in the microclimate at the field or leaf scale (Costes et al. 2013; Pincebourde and Woods 2012; Seidelmann et al. 2016). Changes in microclimate would involve changes in temperature and especially in humidity, which determines leaf wetness and which is expected to influence incubation time (Fouré and Moreau 1992; Jacome and
Schuh 1993). The microclimate hypothesis is supported by the high percentage of the variability in the incubation time that was explained by the phytometer random intercept effect (70\%). This indicates that plant-scale variables, such as microclimate, might greatly affect the length of the incubation period.

Surprisingly, our data did not reveal a positive relationship between spore abundance and density of lesions per exposure day. However, we found that low-stratum non-Musa plant richness had a strong negative effect on the density of lesions per exposure day. The magnitude of this effect, comparable to that of the effect of Musa abundance on the level of inoculum sources according to standardized pathway coefficients, may have "scrambled the signal" of an effect of spore abundance on lesion density. This highlights the importance of field-scale ecological disease regulation mediated by plant richness. Leaf-scale microclimate heterogeneity resulting from plant diversity at the field scale may influence infection efficiency by modifying leaf wetness and also by increasing the diversity of habitats and therefore the diversity
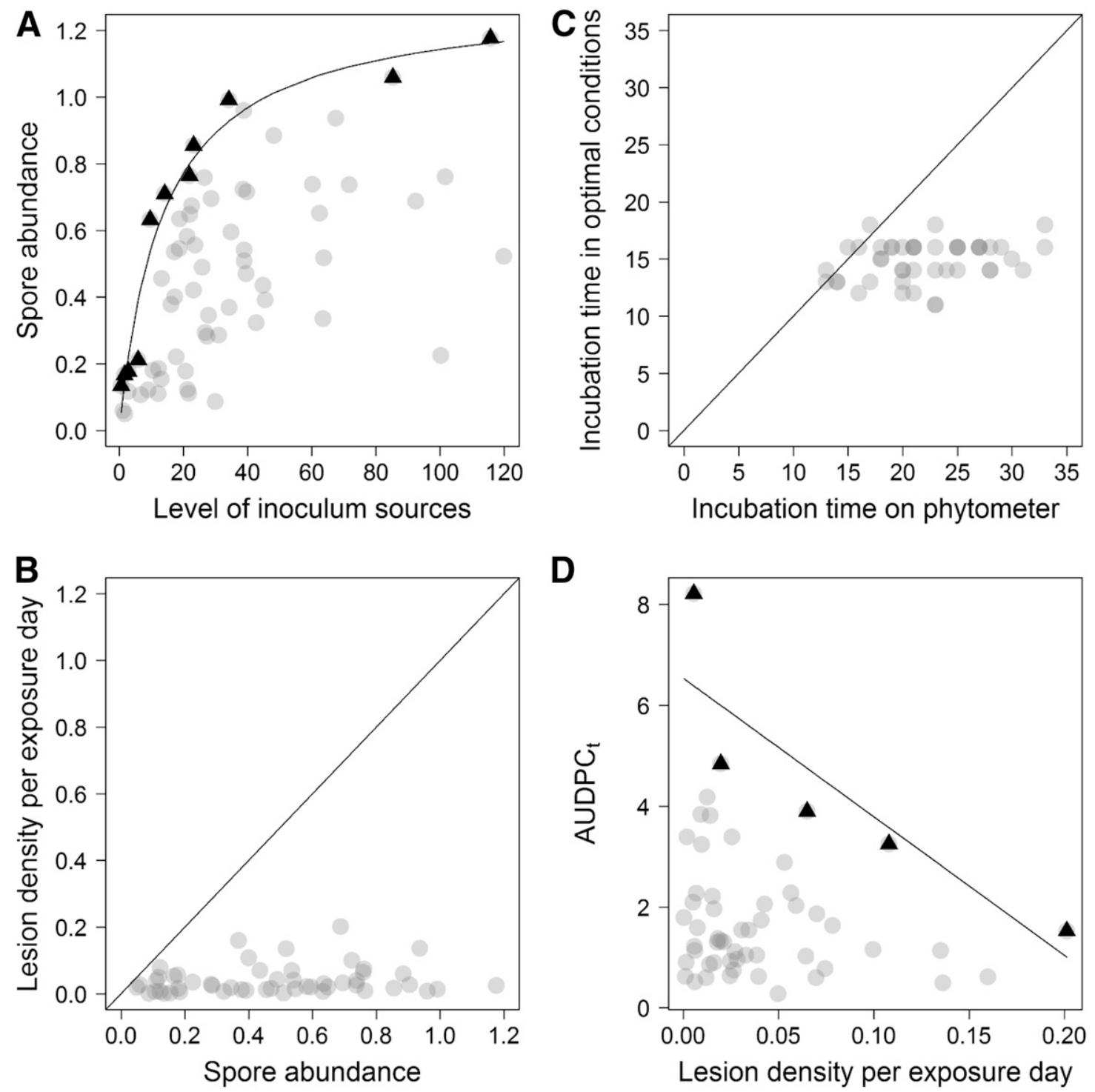

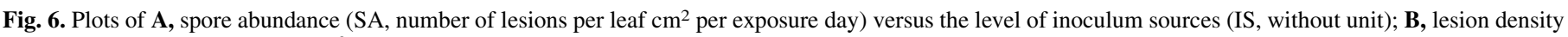

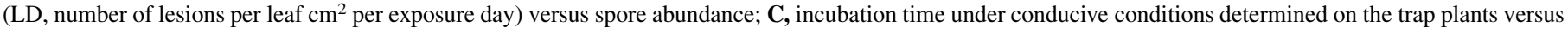

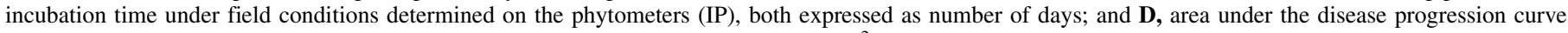

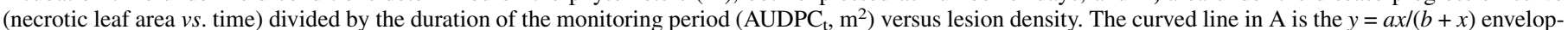

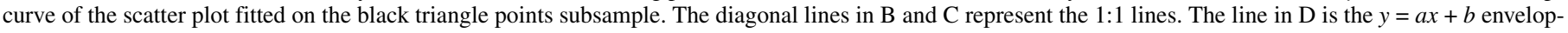

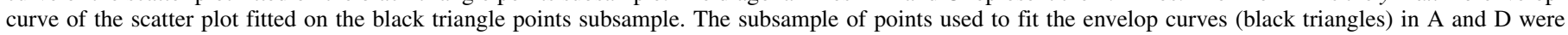

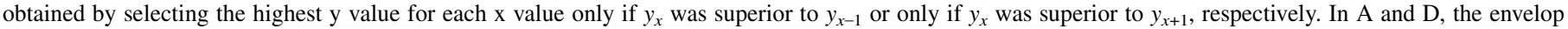
curves, respectively, correspond to the potential spore abundance for a given level of inoculum sources and the potential AUDPC for a given lesion density. 
of epiphyllic microorganisms (Pincebourde and Woods 2012). Interactions with other microorganisms that may reduce BLSD infection efficiency may occur during the epiphyllic growth of M. fijiensis before stomatal penetration (Beveraggi 1992). Epiphyllic interactions were proposed by Meredith (1970) to explain the decreased $M$. fijiensis infection efficiency on older banana leaves. More recently, Ceballos et al. (2012) isolated different epiphyllic bacterial populations with different antifungal properties from various banana genotypes.

Unexpectedly (Table 1), disease severity $\left(\mathrm{AUDPC}_{\mathrm{t}}\right)$ was negatively affected by lesion density. Higher lesion density should have resulted in higher necrotic formation and higher disease severity as

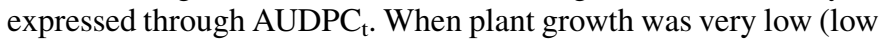
$\mathrm{AUPC}_{t}$ of total leaf area), the progression of leaf necrosis was almost equivalent to the progression of leaf area, as indicated by

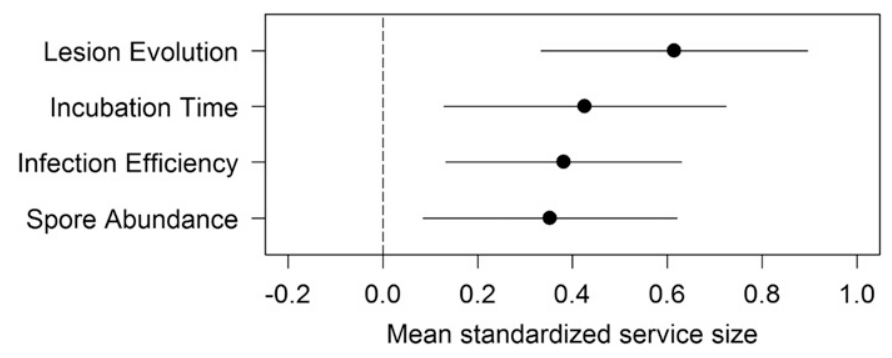

Fig. 7. Regulation of spore abundance, infection efficiency, incubation time, and severity of black leaf streak disease in field plots. Values are means (black dots) \pm SD (horizontal black bars) of standardized regulation values measured in the plots. Values $>0$ indicate regulation, i.e., a reduction in the disease parameter value relative to the expected parameter value. the small gap between $\mathrm{AUDPC}_{\mathrm{t}}$ and $\mathrm{AUPC}_{\mathrm{t}}$ of total leaf area (Supplementary Fig. S2). This suggests that necrotic formation was highly dependent on total leaf area. Since lesions cause leaf necrosis, lesion density negatively affects plant growth and subsequently necrotic formation because less substrate for necrotic formation is available, as confirmed by the negative relationship that we found between $\mathrm{AUPC}_{\mathrm{t}}$ of total leaf area and lesion density. Moreover, this resource effect is probably reinforced in situations where biomass production is limited by an important competition for light and where the crop is more susceptible to pest damage (Poeydebat et al. 2016).

It appears that describing the effect of the disease on the crop by monitoring disease symptoms and necrotic formation only may underestimate this effect because it does not account for important physiological effects that affect biomass production. A broader evaluation of disease impact should take into account such "invisible" biomass production (Supplementary Fig. S3). Experimental design including measurements of potential growth (without disease) or crop growth simulation models may be useful to better represent the true effect of the disease on the crop.

We did not find any effect of canopy openness on BLSD parameters. This contrasts with previous results showing that shade could reduce BLSD severity in plantains (Norgrove and Hauser 2013). Because most of the BLSD development stages are dependent on temperature, humidity, leaf wetness or rainfall events and splashes (Fouré 1982; Fouré and Moreau 1992; Gauhl 1994; Jacome and Schuh 1992; Jacome and Schuh 1993; Jacome et al. 1991), some authors suggested that the disease regulation associated with canopy openness could be due to (i) the prevention of dew deposition on leaves (Calpouzos 1955), (ii) modification of field temperature and humidity (Mariño et al. 2016), and (iii) the reduction of

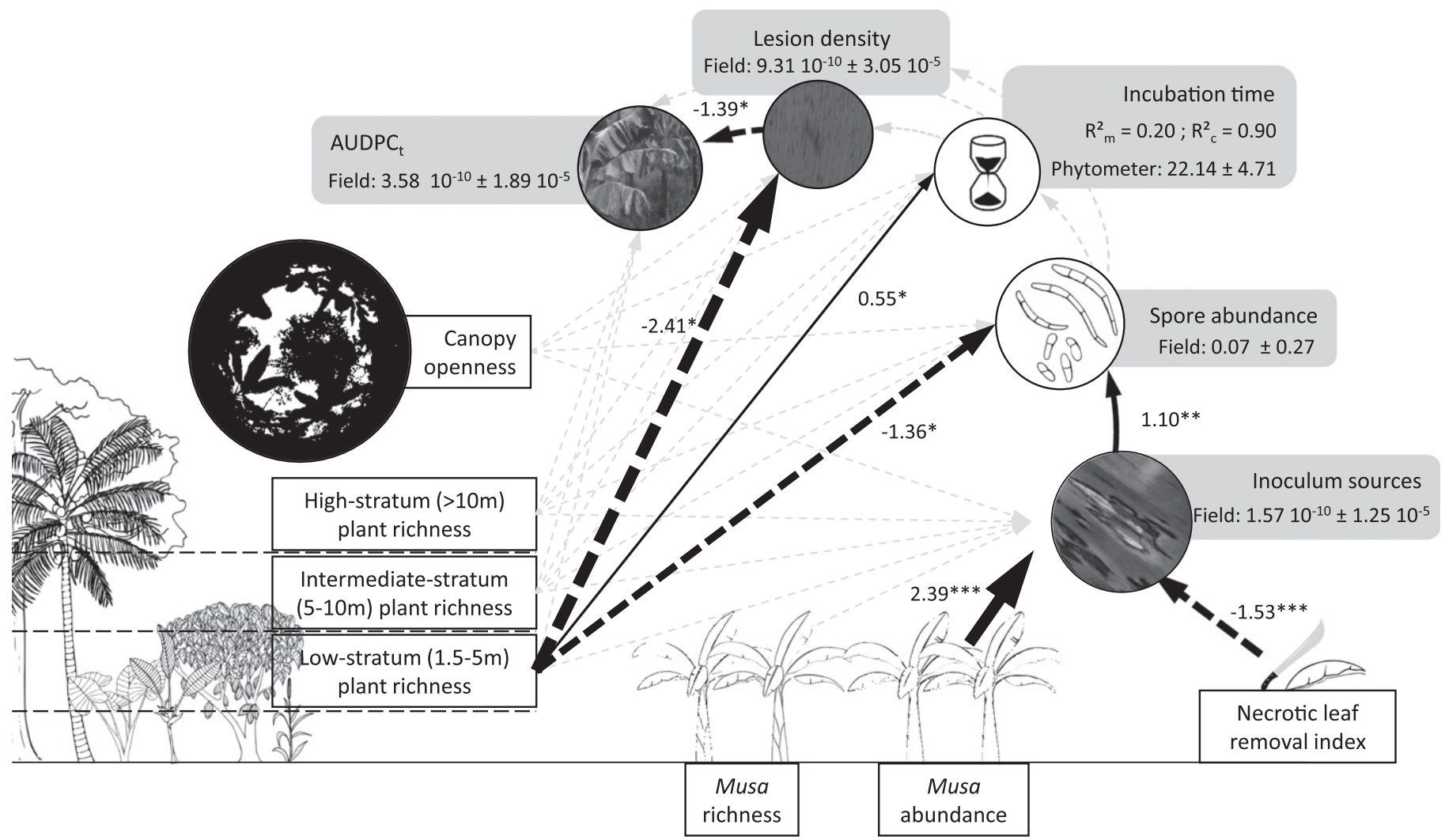

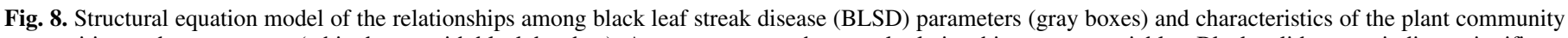

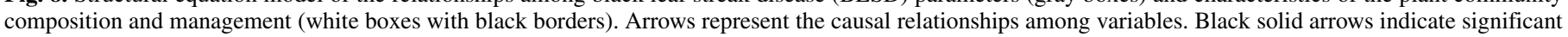

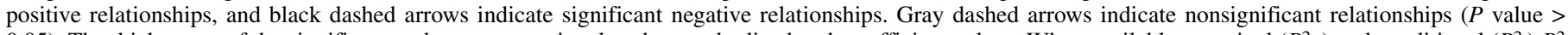

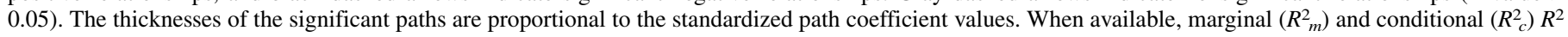

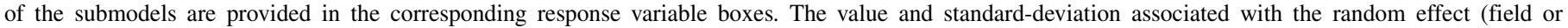
phytometer) in each submodel are provided in the corresponding response variable box. 
rainfall penetration to the understory (Mouen Bedimo et al. 2010). However, canopy openness may not be a good indicator of such processes. For example, Soto-Pinto et al. (2002) found that the number of plant strata, but not shade cover, was related to the severity of coffee leaf rust. We suspect that canopy effects may result from complex structural arrangements that are not described by canopy openness. Perhaps canopy porosity, that can be defined as the ability of the air to go through the canopy or as the sum of the "holes" in the canopy (Tivoli et al. 2013), could be more relevant than canopy openness to disease development, i.e., air and water movement within canopies might be better described by porosity than openness. Canopy porosity, however, is difficult to define and assess (Tivoli et al. 2013). In the case of cocoa pod rot, Gidoin et al. (2014) found that canopy tree structure was a good indicator for disease regulation. Future research should examine the effect of canopy structure on the disease.

Our study has documented field-scale ecological regulation of BLSD in plant-diversified agroecosystems. Moreover, we showed that this regulation involved, to different degrees, several disease parameters, i.e., spore abundance, infection efficiency, incubation time, and disease severity. Our results also indicate that this ecological regulation of BLSD occurs early during disease development (before lesion formation). The regulation was mainly related to the plant richness in the low stratum ( 1.5 to $5 \mathrm{~m}$ high). The relative importance of the 1.5 to $5 \mathrm{~m}$ plant height stratum in regulating the banana BLSD may be explained by the close proximity of the crowns of non-Musa and Musa plants in this height range (Table 1). The overall regulation effect of plant richness on BLSD may also be explained by a positive effect of plant diversity on the tolerance of Musa plants related to an improvement of environmental conditions, such as soil properties (Haggar et al. 2011; Mobambo et al. 1994; Ratnadass et al. 2012). However, data here did not allow testing for this hypothesis.

A structural equation model is the combination of several linear models in which the variables can be both explanatory and response variables (Lefcheck 2016). Therefore, this integrative approach is useful to validate a set of causal relationships describing a system and including indirect or cascading effects. This statistical method is an interesting alternative to classical multivariate analysis. Our study demonstrates the relevance of SEM to disentangle complex ecological mechanisms, and in particular the ecological regulation of plant disease. Our findings promisingly tend to support the idea that agroecosystem diversification can lead to a moresustainable control of BLSD and suggest how management of the plant community within banana-based agroecosystems could promote the ecological regulation of BLSD. First, removing necrotic leaves on the banana plants in a field is an effective way to reduce local inoculum sources. Second, plant richness should be promoted because it (i) reduces spore propagation at the local scale (likely due to a barrier effect and wind pattern disturbance, rather than to a host dilution effect), (ii) increases the incubation time (possibly because of changes in the leaf-scale microclimate that increase leaf wetness duration and delay lesion formation), and (iii) reduces lesion density (possibly due to leaf-scale microclimate effects and to the enhancement of epiphyllic microorganisms that may inhibit $M$. fijiensis). Further studies are needed to provide additional evidence for the mechanisms underlying the ecological regulation of BLSD reported here. Future research should also focus on developing new descriptors of the impact of the disease on the crop, including physiological slowdown and "invisible" yield losses.

The absence of a relationship between Musa abundance and nonMusa plant richness shows that banana agroecosystems can be diversified without reducing the density of the cash crop. In some of the plots in the current study, which involved cultivation of banana for local consumption rather than for export, Musa density exceeded that of commercial export farms (which is generally about 2,000 plants per hectare) (Fig. 4), partly because the farmers maintained several suckers on a mother plant, which resulted in banana plant clumps. However, our data reflects a trade-off between abundance of Musa and nonMusa plants (Fig. 4A), likely to be related to competition for resources (or yield losses) that can increase with noncrop plant abundance. This suggests that, from a farmer point of view, it would be more feasible to increase non-Musa plant richness, rather than abundance, and therefore to mobilize regulation processes related to plant community composition rather than to host dilution.

Because noncrop plant abundance cannot be increased without limit, farmers should carefully select noncrop plants to optimize the complexity of the canopy in order to limit spore dispersal and to promote potential microclimate effects and microbial interactions that limit disease development. Farmers may also find that they can help maintain yield and income by selecting non-Musa plants that promote additional positive plant-plant interactions (complementarity), such as nitrogen transfer (Daudin and Sierra 2008), hydraulic lift (Pang et al. 2013; Sekiya et al. 2011), soil enrichment (Isaac et al. 2007), or soil pathogen regulation (Djigal et al. 2012), or that provide an additional source of income (other crops) (Cerda et al. 2014; Rice 2011).

\section{ACKNOWLEDGMENTS}

We thank I. Rodriguez Arias for his valuable help in tree identification. We thank W. Rodriguez and C. Lynch from APPTA (Association of Small Producers of Talamanca) for linking us to Talamanca farmers and for technical assistance. We thank O. Arias Rosabal from AgriBio Costa Rica (http://www. agribiocr.com/index.php/en/) for providing us with the in vitro plants.

\section{LITERATURE CITED}

Beveraggi, A. 1992. Etude des interactions hôte-parasite chez des bananiers sensibles et résistants inoculés par Cercospora fijiensis responsables de la maladie des raies noires. Université de Montpellier, Montpellier, France.

Bolker, B. M., Brooks, M. E., Clark, C. J., Geange, S. W., Poulsen, J. R., Stevens, M. H. H., and White, J. S. S. 2009. Generalized linear mixed models: A practical guide for ecology and evolution. Trends Ecol. Evol. 24: 127-135.

Boudreau, M. A. 2013. Diseases in intercropping systems. Annu. Rev. Phytopathol. 51:499-519.

Boudrot, A., Pico, J., Merle, I., Granados, E., Vilchez, S., Tixier, P., Filho, E. M. V., Casanoves, F., Tapia, A., Allinne, C., Rice, R. A., and Avelino, J. 2016. Shade effects on the dispersal of airborne Hemileia vastatrix uredospores. Phytopathology 106:572-580.

Brun, J. 1963. La cercosporiose du bananier en Guinée. Etude de la phase ascosporée du Mycosphaerella musicola Leach. Thèse de Doctorat. Université de Paris, Paris

Burt, P. J. A., Rosenberg, L. J., Rutter, J., Ramirez, F., and Gonzales, H. 1999. Forecasting the airborne spread of Mycosphaerella fijiensis, a cause of black Sigatoka disease on banana: estimations of numbers of perithecia and ascospores. Ann. Appl. Biol. 135:369-377.

Burt, P. J. A., Rutter, J., and Ramirez, F. 1998. Airborne spore loads and mesoscale dispersal of the fungal pathogens causing Sigatoka diseases in banana and plantain. Aerobiologia 14:209-214.

Calpouzos, L. 1955. Page 70 in: Studies on the Sigatoka Disease of bananas and its fungus pathogen. Atkins Gdn. Res. Lab., Cuba.

Ceballos, I., Mosquera, S., Angulo, M., Mira, J. J., Argel, L. E., Uribe-Velez, D., Romero-Tabarez, M., Orduz-Peralta, S., and Villegas, V. 2012. Cultivable bacteria populations associated with leaves of banana and plantain plants and their antagonistic activity against Mycosphaerella fijiensis. Microbiol. Ecol. 64:641-653.

Cerda, R., Deheuvels, O., Calvache, D., Niehaus, L., Saenz, Y., Kent, J., Vilchez, S., Villota, A., Martinez, C., and Somarriba, E. 2014. Contribution of cocoa agroforestry systems to family income and domestic consumption: Looking toward intensification. Agrofor. Syst. 88:957-981.

Churchill, A. C. L. 2011. Mycosphaerella fijiensis, the black leaf streak pathogen of banana: Progress towards understanding pathogen biology and detection, disease development, and the challenges of control. Mol. Plant Pathol. 12:307-328.

Costes, E., Lauri, P.-E., Simon, S., and Andrieu, B. 2013. Plant architecture, its diversity and manipulation in agronomic conditions, in relation with pest and pathogen attacks. Eur. J. Plant Pathol. 135:455-470.

Daudin, D., and Sierra, J. 2008. Spatial and temporal variation of belowground $\mathrm{N}$ transfer from a leguminous tree to an associated grass in an agroforestry system. Agric. Ecosyst. Environ. 126:275-280. 
de Lapeyre de Bellaire, L., Essoh Ngando, J., Abadie, C., Chabrier, C., Blanco, R., Lescot, T., Carlier, J., and Côte, F. 2009. Is chemical control of Mycosphaerella foliar diseases of bananas sustainable? Acta Hortic.: 161-170.

de Lapeyre de Bellaire, L., Foure, E., Abadie, C., and Carlier, J. 2010. Black leaf streak disease is challenging the banana industry. Fruits 65:327-342.

Deheuvels, O., Avelino, J., Somarriba, E., and Malezieux, E. 2012. Vegetation structure and productivity in cocoa-based agroforestry systems in Talamanca, Costa Rica. Agric. Ecosyst. Environ. 149:181-188.

Djigal, D., Chabrier, C., Duyck, P.-F., Achard, R., Quénéhervé, P., and Tixier, P. 2012. Cover crops alter the soil nematode food web in banana agroecosystems. Soil Biol. Biochem. 48:142-150.

Donzelli, B. G. G., and Churchill, A. C. L. 2007. A quantitative assay using mycelial fragments to assess virulence of Mycosphaerella fijiensis. Phytopathology 97:916-929.

Emebiri, L. C., and Obiefuna, J. C. 1992. Effects of leaf removal and intercropping on the incidence and severity of black Sigatoka disease at the establishment phase of plantains (Musa spp. AAB). Agric. Ecosyst. Environ. 39:213-219.

Fouré, E. 1982. Les cercosporioses du bananier et leurs traitements. Comportement des variétés. Etudes de la sensibilité variétale des bananiers et plantains à Mycosphaerella fijiensis Morelet au Gabon (maladie des raies noires). I. Incubation et évolution de la maladie. Fruits 37:749-759.

Fouré, E., Grisoni, M., and Zurfluh, R. 1984. A study of the varietal sensitivity of banana and plantain trees to Mycosphaerella fijiensis Morelet and some biological characteristics of the black furrow disease in Gabon. Fruits 39: 365-378.

Fouré, E. 1985. Black leaf streak disease of banana and plantains (Mycosphaerella fijiensis Morelet) study of the symptoms and stages of the disease in Gabon. IRFA, París.

Fouré, E., and Moreau, A. 1992. Contribution à l'étude épidémiologique de la cercosporiose noire dans la zone de Moungo au Cameroun de 1987 à 1989. Fruits 47:3-16.

Fouré, E., Mouliom-Pefoura, A., and Mourichon, X. 1990. Etude de la sensibilité variétale des bananiers et des plantains à M. fijiensis Morelet au Cameroun. Caractérisation de la résistance au champ de bananiers appartenant à divers groupes génétiques. Fruits 45:339-345.

Frazer, G. W., Canham, C. D., and Lertzman, K. P. 1999. Gap Light Analyzer (GLA), Version 2.0: Imaging software to extract canopy structure and gap light transmission indices from true-colour fisheye photographs, user's manual and program documentation. Simon Fraser University, Burnaby, British Columbia, and the Institute of Ecosystem Studies, Millbrook, New York.

Gargiullo, M., Magnuson, B., and Kimball, L. 2008. A Field Guide to Plants of Costa Rica. Oxford University Press, Oxford.

Gauhl, F. 1994. Epidemiology and ecology of Black Sigatoka (Mycosphaerella fijiensis Morelet) on plantain and banana (Musa spp.) in Costa Rica, Central America. Ph.D. thesis. Göttingen University.

Gidoin, C., Avelino, J., Deheuvels, O., Cilas, C., and Bieng, M. A. N. 2014. Shade tree spatial structure and pod production explain frosty pod rot intensity in cacao agroforests, Costa Rica. Phytopathology 104:275-281.

Gómez-Rodriguez, O., Zavaleta-Mejı, E., Gonzalez-Hernandez, V., Livera-Munoz, M., and Cárdenas-Soriano, E. 2003. Allelopathy and microclimatic modification of intercropping with marigold on tomato early blight disease development. Field Crops Res. 83:27-34.

Haggar, J., Barrios, M., Bolaños, M., Merlo, M., Moraga, P., Munguia, R., Ponce, A., Romero, S., Soto, G., Staver, C., and Virginio, E. d. M. F. 2011. Coffee agroecosystem performance under full sun, shade, conventional and organic management regimes in Central America. Agroforest. Syst. 82.

Isaac, M. E., Timmer, V. R., and Quashie-Sam, S. 2007. Shade tree effects in an 8-year-old cocoa agroforestry system: biomass and nutrient diagnosis of Theobroma cacao by vector analysis. Nutr. Cycl. Agroecosyst. 78:155-165.

Jacome, L. H., and Schuh, W. 1992. Effects of leaf wetness duration and temperature on development of black sigatoka disease on banana infected by Mycosphaerella fijiensis var difformis. Phytopathology 82:515-520.

Jacome, L. H., and Schuh, W. 1993. Effect of temperature on growth and conidial production in vitro and comparison of infection and aggressiveness in vivo among isolates of Mycosphaerella fijiensis var. difformis. Trop. Agric. Trinidad 70:51-59.

Jacome, L. H., Schuh, W., and Stevenson, R. E. 1991. Effect of temperature and relative humidity on germination and germ tube development of Mycosphaerella fijiensis var. difformis. Phytopathology 81:1480-1485.

D. R. Jones, ed. 2000. Diseases of Banana, Abaca and Enset. CAB International, Wallingford, UK.

Lefcheck, J. S. 2016. piecewiseSEM: Piecewise structural equation modelling in $\mathrm{r}$ for ecology, evolution, and systematics. Methods Ecol. Evol. 7:573-579.

Marin, D. H., Romero, R. A., Guzman, M., and Sutton, T. B. 2003. Black Sigatoka: An increasing threat to banana cultivation. Plant Dis. 87:208-222.

Mariño, Y. A., Pérez, M.-E., Gallardo, F., Trifilio, M., Cruz, M., and Bayman, P. 2016. Sun vs. shade affects infestation, total population and sex ratio of the coffee berry borer (Hypothenemus hampei) in Puerto Rico. Agric. Ecosyst. Environ. 222:258-266.
Meredith, D. S., and Lawrence, J. S. 1969. Black leaf streak disease of bananas (Mycosphaerella fijiensis): Symptoms of disease in Hawaï, and notes on the conidial state of the causal fungus. Trans. Br. Mycol. Soc. 52: 459-476.

Meredith, D. S., and Lawrence, J. S. 1970. Black leaf streak disease of bananas (Mycosphaerella fijiensis): Susceptibility of cultivars. Trop. Agric. Trin. 47: 275-287.

Meredith, M. A. 1970. Banana leaf spot disease (Sigatoka) caused by Mycosphaerella musicola Leach. Page 147 in: Commonwealth Mycol. Inst. Phytopathological Papers, Kew, UK.

Mobambo, K. N., Gauhl, F., Vuylsteke, D., Ortiz, R., Pasberggauhl, C., and Swennen, R. 1993. Yield loss in plantain from black sigatoka leaf spot and field performance of resistant hybrids. Field Crops Res. 35:35-42.

Mobambo, K. N., Zuofa, K., Gauhl, F., Adeniji, M. O., and Pasberg-Gauhl, C. 1994. Effect of soil fertility on host response to black leaf streak of plantain (Musa spp., AAB group) under traditional farming systems in southeastern Nigeria. J. Pest Manage. 40:75-80.

Mouen Bedimo, J., Bieysse, D., Nyassé, S., Nottéghem, J., and Cilas, C. 2010. Role of rainfall in the development of coffee berry disease in Coffea arabica caused by Colletotrichum kahawae, in Cameroon. Plant Pathol. 59:324-329.

Mundt, C. C. 2002. Use of multiline cultivars and cultivar mixtures for disease management. Annu. Rev. Phytopathol. 40:381-410.

Newton, A., Begg, G., and Swanston, J. 2009. Deployment of diversity for enhanced crop function. Ann. Appl. Biol. 154:309-322.

Norgrove, L., and Hauser, S. 2013. Black leaf streak disease and plantain fruit characteristics as affected by tree density and biomass management in a tropical agroforestry system. Agrofor. Syst. 87:349-354.

Pang, J., Wang, Y., Lambers, H., Tibbett, M., Siddique, K. H., and Ryan, M. H. 2013. Commensalism in an agroecosystem: hydraulic redistribution by deep-rooted legumes improves survival of a droughted shallow-rooted legume companion. Physiol. Plant. 149:79-90.

Pennisi, E. 2010. Armed and dangerous. Science 327:804-805.

Pincebourde, S., and Woods, H. A. 2012. Climate uncertainty on leaf surfaces: the biophysics of leaf microclimates and their consequences for leafdwelling organisms. Funct. Ecol. 26:844-853.

Pinheiro, J., Bates, D., DebRoy, S., Sarkar, D., and R Core Team. 2017. Linear and nonlinear mixed effects models. R package version 3.1-131.

Poeydebat, C., Carval, D., Lapeyre de Bellaire, L., and Tixier, P. 2016. Balancing competition for resources with multiple pest regulation in diversified agroecosystems: A process-based approach to reconcile diversification and productivity. Ecol. Evol. 6:8607-8616.

Ratnadass, A., Fernandes, P., Avelino, J., and Habib, R. 2012. Plant species diversity for sustainable management of crop pests and diseases in agroecosystems: A review. Agron. Sustain. Dev. 32:273-303.

R Core Team. 2014. R: A language and environment for statistical computing. R Foundation for Statistical Computing, Vienna, Austria. http://www.Rproject.org/

Rice, R. A. 2011. Fruits from shade trees in coffee: How important are they? Agrofor. Syst. 83:41-49.

Rieux, A., Soubeyrand, S., Bonnot, F., Klein, E. K., Ngando, J. E., Mehl, A., Ravigne, V., Carlier, J., and De Lapeyre De Bellaire, L. 2014. Long-distance wind-dispersal of spores in a fungal plant pathogen: Estimation of anisotropic dispersal kernels from an extensive field experiment. PLoS One 9: e103225.

Risède, J. M., Lescot, T., Cabrera, J., Guillon, M., Tomekpé, K., Kema, G. H. J., and Côte, F. 2010. From Science to Field. Banana Case Study- Guide Number 1. Challenging short and mid-term strategies to reduce pesticides in bananas. ENDURE, Paris.

Root, R. B. 1973. Organization of a plant-arthropod association in simple and diverse habitats-Fauna of collards (Brassica oleracea). Ecol. Monogr. 43:95-124.

Sahile, S., Fininsa, C., Sakhuja, P., and Ahmed, S. 2008. Effect of mixed cropping and fungicides on chocolate spot (Botrytis fabae) of faba bean (Vicia faba) in Ethiopia. Crop Prot. 27:275-282.

Schoeny, A., Menat, J., Darsonval, A., Rouault, F., Jumel, S., and Tivoli, B. 2008. Effect of pea canopy architecture on splash dispersal of Mycosphaerella pinodes conidia. Plant Pathol. 57:1073-1085.

Schroth, G., Krauss, U., Gasparotto, L., Duarte Aguilar, J. A., and Vohland, K. 2000. Pests and diseases in agroforestry systems of the humid tropics. Agrofor. Syst. 50:199-241.

Seidelmann, K. N., Scherer-Lorenzen, M., and Niklaus, P. A. 2016. Direct vs. microclimate-driven effects of tree species diversity on litter decomposition in young subtropical forest stands. PLoS One 11:e0160569.

Sekiya, N., Araki, H., and Yano, K. 2011. Applying hydraulic lift in an agroecosystem: Forage plants with shoots removed supply water to neighboring vegetable crops. Plant Soil 341:39-50.

Shipley, B. 2000. A new inferential test for path models based on directed acyclic graphs. Struct. Equ. Modeling 7:206-218.

Shipley, B. 2009. Confirmatory path analysis in a generalized multilevel context. Ecology 90:363-368. 
Somarriba, E., and Harvey, C. 2003. ¿Cómo integrar producción sostenible y conservación de biodiversidad en cacaotales orgánicos indígenas. Agroforesteria Americas 10:12-17.

Soto-Pinto, L., Perfecto, I., and Caballero-Nieto, J. 2002. Shade over coffee: Its effects on berry borer, leaf rust and spontaneous herbs in Chiapas, Mexico. Agrofor. Syst. 55:37-45.

Stover, R. H. 1983. Effet du cercospora noir sur les plantains en Amérique centrale. Fruits 38:326-329.

Stover, R. H., and Simmonds, N. W. 1987. Bananas. 3rd ed. Longman, Essex.
Tivoli, B., Calonnec, A., Richard, B., Ney, B., and Andrivon, D. 2013. Current knowledge on plant/canopy architectural traits that reduce the expression and development of epidemics. Eur. J. Plant Pathol. 135:471-478.

Venables, W. N., and Ripley, B. D. 2002. Modern Applied Statistics with S. 4th ed. Springer, New York.

Winowiecki, L. 2008. Soil biogeochemical patterns in the Talamanca foothills, Costa Rica: Local soil knowledge and implications for agroecosystems. CATIE, Turrialba (Costa Rica) University of Idaho. EUA, Moscow, ID. 